\title{
Darius und der Achämeniden-Stammbaum.
}

\author{
Von C. F. Lehmann-Haupt.
}

Bei der Bestimmung der acht Vorfahren, die nach Darius' Worten im Eingang der Behistun-Inschrift vor ihm Köhige waren, wird immer noch der Fehler gemacht, dass Annahmen in Betracht gezogen werden, die den Vorstellungen des Darius geradeweg s zuwiderlaufen, während doch der einzig richtige Weg nur der sein kann, dass man z u e r s t den Stammbaum, wie ihn sich Darius vorgestellt hat, herzustellen sucht und d a $\mathbf{n}$ a ch zusieht, wie die von diesen Vorstellungen abweichenden Nachrichten zu erklären oder zu bewerten sind.

Auch in Prášek's neuer Darstellung der medischen und persischen Geschichte ${ }^{1}$ ) kehrt dieser Fehler wieder, und da dem Verfasser, der im Uebrigen eine möglichst vollständige Berücksichtigung wie der Quellen so der neueren Literatur anstrebt und dementsprechend auch hier zahlreiche Äusserungen zur Sache anführt ${ }^{2}$ ), meine Ansicht unbekannt geblieben ist, so sei sie hier an etwas offenkundigerer Stelle, als es bisher geschehen ${ }^{3}$ ), nochmals dargelegt. Darius nennt sich (Behist. Col. I $\S 1$ und Beh.a $\$ 1-4)^{4}$ ) "des Hystaspes Sohn, des Arsames Enkel *. Ferner meldet er: "mein Vater ist Hystaspes, des Hystaspes Vater war Arsames, des Arsames Vater Ariaramnes, des Ariaramnes Vater Teispes, des Teispes Vater Achämenes. Deswegen werden wir Achämeniden genannt. Acht meines Geschlechts waren vordem Könige; ich bin der neunte. Duvitâparnam (neususisch šamakmar) sind wir neun Könige".

Also ist für Darius Achämenes der Vater des Teispes und der Grossvater des Ariaramnes, folglich können die bei Herodot VII $11^{5}$ ) zwischen

1) Justin V. Prášek, Geschichte der Meder und Perser bis zur makedonischen Eroberung, I. Band. (Handbücher der alten Geschichte I. Serie. 5. Abteilung. 1. Band) S. $179 \mathrm{ff}$.

2) Ebenda Anm. 1 auf S. 181 ff.

3) Klio II, 1902, S. 341 Anm. 1 (wo auch auf die von Prášek gleichfalls übersehene Aeusserung Krčmar's, Sitzungsber. d. böhm. Ak. d. W. 1902 Nr. 4 verwiesen ist, der selbständig die gleiche Ansicht vertritt) und Verhandlungen des XIII. Or. Kongresses (Hamburg 1902) S. $98 \mathrm{f}$.

4) Ich zitiere nach der Ausgabe von Weissbach und Bang.

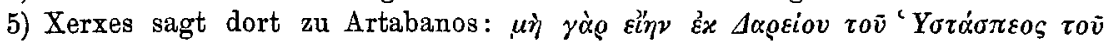
'A

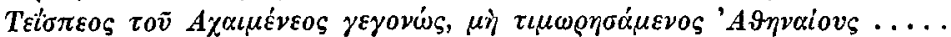


Teispes, ,Achämenes' Sohn', und Ariaramnes eingeschobenen drei Glieder nämlich als ältester ein Kambyses, dann ein Kyros und schliesslich ein Teispes - unmöglich zu den acht Vorgängern gehören, die Darius im Auge hatte!

Und ebenso sicher ist die Tatsache, dass Hystaspes in keinem Sinne als König angesprochen werden kann. Denn während Ariaramnes und Arsames, des Hystaspes Grossvater und Vater, wie ich früher schon betonte ${ }^{1}$ ), unter medischer Oberhoheit Unterkönige der Persis gewesen sein werden, ebenso wie Kyros und Kambyses, des grossen Kyros Grossvater und Vater, im gleichen Sinne nach der babylonischen Cylinderinschrift des Kyros Unterkönige von Anzan waren, so ist in der Organisation, die Kyros seinem persischen Reiche gab, für ein solches Unterkönigtum keinerlei Raum. Unter Darius verwaltete Hystaspes die Satrapien Parthien und Hyrkanien; dass er bereits unter Kyros und Kambyses in einem der beiden Gebiete, wenn nicht schon in beiden, die Verwaltung führte, ist anzunehmen ${ }^{2}$ ), aber sicher nicht mit dem Titel König lchšayathiya $\left.{ }^{3}\right)^{4}$ ).

Demnach steht ausser Frage, dass nach Darius' Vorstellung die Reihe seiner unmittelbaren Vorfahren wie folgt lautet: Achämenes, Teispes, Ariaramnes, Arsames, Hystaspes, von denen die vier ersteren Könige waren. Die weiteren vier Könige, die nötig sind um die Neun voll zu machen, sind ohnehin durchaus klar. Es - sind Kyros der Grosse (II) und Kambyses II, auf die Darius ausdrücklich Bezug nimmt ${ }^{5}$ ), und deren gleich-

1) An den S. 493 Anm. 3 angeführten Stellen. Ebenso jetzt Weisbach (brieflich) bei Príšek, S. 181 Anm. 1 a.

2) So richtig Prášek a. a. O. S. 205.

3) Dem entspricht es auch, dàss bei Artaxerxes II, der all seinen Vorgängern bis zurück zu Darius den Königstitel gibt, Hystaspes nicht als König (Kȟ̆ayathiya) bezeichnet wird: Inschriften von Susa und von Hamadan : ...... ${ }_{n}$ des Xerxes, welcher des Kö nig s Darius Sohn war, des Darius, (welcher) des Hystaspes Sohn (war) ${ }^{*}$ - Artaxerxes III verfährt zwar in der Inschrift von Persepolis ebenso; (....) ${ }_{n}$ Xerxes war des Königs Darius Sohn, Darius war der Sohn (eines) Namens Hystaspes “, dann heisst es aber weiter: „Hystaspes war der Sohn (eines) Namens Arsames“. Aus der Anführung des Arsames, der für Darius als König galt, ersehen wir, dass Artaxerxes III bei seiner Aufzühlung nur die achämenidischen Grosskönige (khšayathia kšayathiyânâm, ,König der Könige') im Auge hat und nur sie - anders als Darius, der seine Legitimität zu erweisen hatte, - als Könige bezeichnet. Für Artaxerxes II ist dieser Standpunkt wenigstens nicht ersichtlich. Immerhin kann man seiner Aussage a 1 l e in keine volle Beweiskraft beilegen, sondern sie nur sekundär neben dem in Haupttexte Ausgeführten zur Geltung bringen.

4) Auf das spezifische $\mathrm{K} \ddot{\mathrm{ni}} \mathrm{gtum}$ des Hystaspes dürfen sich also diejenigen sicher nicht berufen, die die Frage, ob Zoroaster (Zarathustra Spitama) um 1000 v. Chr. anzusetzen sei (so Ed. Meyer, Berl. Sitzungsber. und Zeitschr. f. vergleichende Sprachforschung 4, 1908, S. 16) oder zur Zeit des Hystaspes gelebt hat, im letzteren Sinne - wie u. a. auch ich - entscheiden möchten. Näheres zu der Frage demnächst von iranistischer Seite in dieser Zeitschrift.

5) Beh. Col. I \$ 10: „Einer namens Kambyses, des Kyros Sohn, aus unserem Geschlechte war vordem hier König". 
namige Grossväter, Kyros I. und Kambyses I. Als Vater Kyros' I. nenut der Kyros-Cylinder den Šišpiš-Teispes ${ }^{1}$ ).

Somit sind, was nicht nachdrücklich genug betont werden kann, Darius' Angaben vollkommen eindeutig. Nach seiner Anschauung waren Stammbaum und Königsreihe, wie folgt, gestaltet:

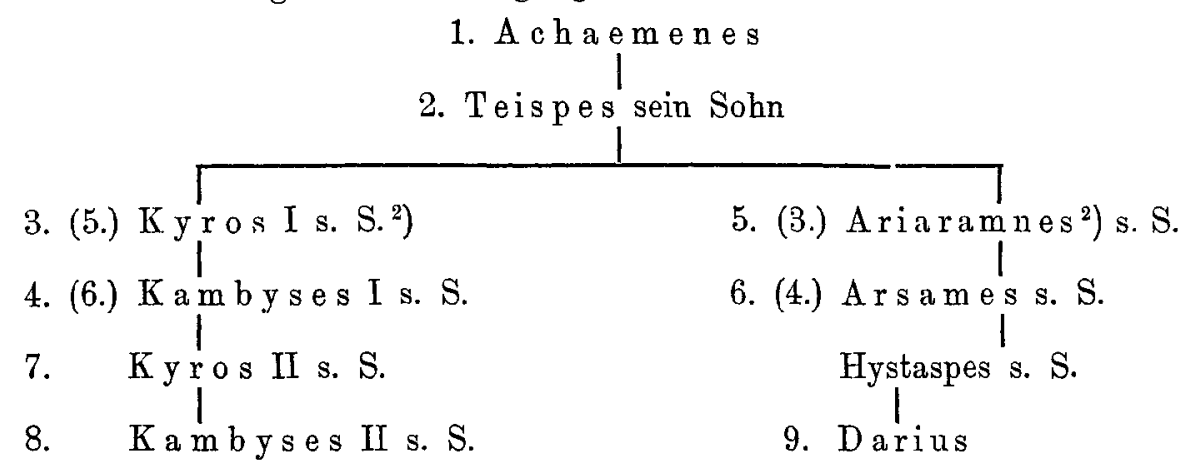

So zeigte der inschriftliche Befund von vornherein, dass für dunit $\hat{a}-$ tarnam, wie man bis vor kurzem las, nur die Deutung "in zwei Reihen", die Oppert vorgeschlagen hatte, zutreffen konnte und dass diejenigen im Unrecht waren, die wieder und wieder die Uebersetzung „von Alters her" bevorzugten, die einen Stanmbaum in gerader Linie ermöglicht. Es ist daher sachlich nur eine Bestätigung, kein Novum, dass, wie die neueste Vergleichung der Bisutun-Inschrift seitens der englischen Forscher gezeigt hat, im Original duvitâparnam dasteht, was nur als "zweifach " in zwei Reihen" gedeutet werden kann ${ }^{3}$ ).

Völlig gleichwertig in ihrem Iraniertum waren die beiden Reihen, die persische und die anzanische Linie, wahrscheinlich nicht. Die uniranische Namensform Kuraš, auf die Andreas ${ }^{4}$ ) mit Recht die Aufmerksamkeit gelenkt hat, lässt vermuten, dass Kyros zwar sicher (gegen Andreas) väterlicherseits rein iranischer und achämenidischer Abstammung war, dass aber mütterlicherseits ein Zusatz anzanischen, also nicht indogermanischen (und nicht semitischen) Blutes für ihn in Betracht kommt. Der anzanische

1) Dagegen geht die Backsteinlegende des Cyrus von Warka oder von Senkereh nicht über Kambyses I zurück. Prúsek's wiederholte Berufung auf die ,Senkerehtafel' für Teispes als Cyrus' II Urgrossvater beruht auf einem Versehen.

2) Ob Kyros I oder Ariaramnes der ältere Bruder war, steht dahin: vgl. aber A. Hoffmann-Kutschke, Philologus 1907, S. 187 ff., und Altpersisches, Neue Prenss. Zeitg. Nr. 243 Beil. 1 (24. Mai 1908): „Die Linie des Darius und des Wischtaspa ist die jüngere (gr.

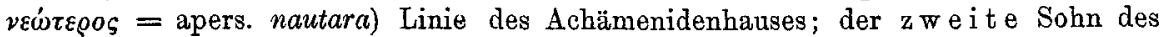
Tschischpisch Ariaramna, ist Nautara, der Sohn von ihm wie seine Nachfolger Naotairja (awest. für Nautar-ja)".

3) (Thompson und King) The Sculptures and Inscriptions of Darius the Great on the rock of Behistân in Persia 1907. - Dazu Weissbach ZDMG, 61, S. 724 f., Hoffmann-Kutschke, Philologiae Novitates III Heft 3/4 S. $102 \mathrm{f}$.

4) Verhandl. des XIII. Or.-Kongr. s. $93 \mathrm{ff}$. 
Zweig aber hatte nach der historischen Entwickelung, wenn nicht sogar dem Geburtsalter nach ${ }^{1}$ ), den Vorrang, und so lässt sich vermuten, dass der Einschub jener drei Glieder in den Stammbaum des Xerxes dem Bestreben seinen Ursprung verdankte, die grossen Herrscher der anzanischen Linie durch Einfügung einer Reihe ihnen gleichnamiger Vorgänger in den ungespaltenen Stammbaum der Achämeniden enger mit dem persischen Zweige zu verknüpfen.

Doch damit überschreiten wir bereits die dieser Betrachtung gezogene Grenze. In diesem, dem internationalen Historikertage gewidmeten Hefte unserer Zeitschrift gilt es im wesentlichen nur das urkundlich Feststellbare zu betonen. Es kam darauf an, Darius' Vorstellungen klarzulegen die Frage, ob er mit ihnen, wie ich allerdings glaube ${ }^{2}$ ), im Rechte war, steht auf einem anderen Blatte und soll heute nicht erörtert werden.

Berlin.

1) Vgl. S. 495 Anm. 2.

2) An den S. 493 Anm. 3 angeführten Stellen habe ich mich auch für die Geschichtlichkeit des Achämenes, den ich nicht als einen mythischen Heros eponymos betrachten möchte, erklärt und angenommen, dass Achämenes' Herrschaft (5 Generationen vor Darius : um 700) vor die Begründung des Mederreiches (677) falle. "Erst sein Sohn Teispes oder dessen Söhne und Nachfolger in Persien und Anšan gerieten in medische Abhängigkeit". Dass andererseits Kyros den Achämenes nicht unter seinen Vorfahren nenne, erkläre sich "ganz wohl, wenn der Name Achämeniden speziell dem persischen $\mathrm{Zweige}$ zukam, der sich reiner erhalten hatte, als der anzanische“. 